\title{
Children with Nephrotic Syndrome Suffer from Cerebral Venous Thrombosis
}

\author{
Zheng-Kun Xia*, Xiao Yang*, Zhong-Min Fan*, Yuan-Fu Gao*, Chunlin Gao, Jing Li, Xu He, Pei Zhang, Tao Sun, Zhuo Shi, Hongjun Peng \\ and Min Xu \\ Department of Pediatrics, Nanjing Jinling Hospital, China
}

\begin{abstract}
Hypercoagulability is a common complication in children with nephrotic syndrome and may cause venous thrombosis. This study explored the effectiveness of urokinase and low-molecular-weight (LMW) heparin used in conjunction in seven children with nephrotic syndrome complicated by intracranial venous thrombosis. The urokinase dose was 2,000-4,000 u/kg/day initially, with a pulse dose of 20,000-40,000 u given within 15-30 minutes and the remainder was pump-infused. From day 2, a dose of 2,000 u/kg/day was infused via the pump, and the total course duration was 3 to 7 days. During treatment, thrombin time (TT) and activated partial thromboplastin time (APTT) were tested three times per week, and particular attention was given to any bleeding. LMW heparin was used at a dosage of 100-120 anti-Xa IU/kg once or twice per day, given by abdominal subcutaneous injection for two weeks. The antiplatelet drug, dipyridamole 3-5 mg/kg, was also given orally two or three times per day for three months. In this study, the early use of urokinase, LMW heparin and anti-platelet drugs had good effect, the need for preventive therapy and early diagnosis of this complication in nephrotic syndrome should be given wider clinical consideration.
\end{abstract}

Keywords: Nephrotic syndrome; Intracranial venous thrombosis; Urokinase; Children

\section{Introduction}

It is well known that nephrotic syndrome leads to a hypercoagulable state and thrombosis is therefore a common complication [1-3]. The pathophysiology of this coagulopathy includes renal loss of antithrombin III, an increase in coagulation factors and fibrinogen, and the effects of the drugs used in treatment, which include hormones and diuretics.

In children with nephrotic syndrome, the occurrence of deep venous thrombosis of the limbs and renal venous thrombosis are well documented $[1,4]$. In contrast, the diagnosis of cerebral venous sinus thrombosis (CVST) complicating childhood nephritic syndrome appears to be extremely rare $[1,5,6]$. In the largest study carried out so far, the incidence was 0.67 cases per 100,000 children per year; this is due by a combination of its low incidence, the complex and diverse associated clinical manifestations, lack of specificity of diagnostic tests and the high misdiagnosis rate. In this report, we present seven cases that demonstrate this rare complication.

\section{Methods}

\section{Patients}

During the period from December 2009 to October 2012, we observed seven children with Nephrotic Syndrome (NS) who developed CVST. The patients (all boys, aged from 8 to 13 years) were all entered into our study after informed consent was obtained. The episodes of CVST occurred two to five months after the onset of the nephrotic syndrome.

\section{Investigations}

All of the children underwent blood tests, including activated partial thromboplastin time (APTT), fibrinogen degradation products (FDPs), prothrombin time (PT), thrombin time (TT), tests of blood and plasma viscosity, and brain CT or MRI. Digital subtraction angiography (DSA) remains the method of choice for the assessment on cases of CVST that complicate NS, but due to the invasive nature of the test and high cost, all the children were diagnosed by CT or MRI brain scans with associated magnetic resonance venography (MRV) and examination of the blood coagulation system (PT, FDPs and hemo rheology).

\section{Treatment}

Urokinase: The initial dose of urokinase was 2,000-4,000 u/kg/day, with a first pulse of 20,000-40,000 u given within 15-30 minutes, and the remainder infused over 24 hours via pump injection. The dose on the second day was $2,000 \mathrm{u} / \mathrm{kg}$, which was infused over 24 hours via a pump; the course of treatment ranged from three to seven days. During the treatment period, TT and APTT were tested three times every week with particular attention to the clotting tests $[7,8]$.

Low-molecular-weight heparin (LMW): We administered LMW heparin by subcutaneous injection at a dose of 100-120 anti-Xa IU/ $\mathrm{kg}$ once or twice per day for two weeks. After two weeks, the patients received therapy with warfarin at a dosage of 1-2.5 mg once or twice per day for one to three months.

*Corresponding authors: Zheng-Kun Xia, Department of Pediatrics, Nanjing Jinling Hospital, 305 East Road, Zhong Shan, Nanjing 210002, P.R. China, Tel: (+86 25) 80861386; E-mail: njxzk@126.com

Xiao Yang, Department of Pediatrics, Nanjing Jinling Hospital, 305 East Road ZhongShan, Nanjing 210002,P.R.China. Tel: (+86 25) 80861386; E-mail: zyu87@163.com

Zhongmin Fan, Department of Pediatrics, Nanjing Jinling Hospital, 305 East Road ZhongShan, Nanjing 210002,P.R.China. Tel: (+86 25) 80861386; E-mail: fanzhongmin@126.com

Yuanfu Gao, Department of Pediatrics, Nanjing Jinling Hospital, 305 Eas Road ZhongShan, Nanjing 210002,P.R.China. Tel: (+86 25) 80861386; E-mail: gaoyf9199@163.com

Received January 03, 2014; Accepted February 18, 2014; Published February 25,2014

Citation: Xia ZK, Yang X, Fan ZM, Gao YF, Gao C, et al. (2014) Children with Nephrotic Syndrome Suffer from Cerebral Venous Thrombosis. J Nephro Therapeutic S11: 005. doi:10.4172/2161-0959.S11-005

Copyright: (c) 2014 Xia ZK, et al. This is an open-access article distributed unde the terms of the Creative Commons Attribution License, which permits unrestricted use, distribution, and reproduction in any medium, provided the original author and source are credited. 
Citation: Xia ZK, Yang X, Fan ZM, Gao YF, Gao C, et al. (2014) Children with Nephrotic Syndrome Suffer from Cerebral Venous Thrombosis. J Nephrol Therapeutic S11: 005. doi:10.4172/2161-0959.S11-005

Page 2 of 4

\section{Anti-platelet drugs}

Patients received dipyridamole $3-5 \mathrm{mg} / \mathrm{kg}$ two to three times per day for three months. Additional therapy.

During treatment with these drugs, the patients also received LMW dextran, which acted to raise intracranial pressure, and anti-epileptic agents if necessary.

\section{Results}

\section{Presenting features}

The seven children all had acquired NS, including three cases of simple-type NS, two cases of nephritic-type NS (including two cases of steroid-dependent NS and three cases of steroid-resistant NS). Renal biopsies were consistent with minimal change glomerulopathy in two cases, mesangial proliferative glomerulonephritis in two cases and membranoproliferative golmerulonephritis in two cases and membranoproliferative glomerulonephritis in one. Diagnostic criteria of nephritic Syndrome were according to the Branch of Chinese Medical Sciences Nephrology Momentum group in 2001.

The presenting symptoms included headache and vomiting $(\mathrm{n}=5)$, dizziness, $(n=2)$, convulsions $(n=2)$, and drowsiness $(n=1)$, altered consciousness $(n=1)$ and vague neurological symptoms $(n=1)$.

CT and MRI brain scans in five cases demonstrated that three patients had superior sagittal sinus thrombosis, one a transverse sinus thrombosis and one a sigmoid sinus thrombosis.

\section{Post-treatment findings}

After treatment with urokinase, LMW heparin and dipyridamole, all the symptoms of CVST disappeared. Clinically, all seven patients had complete remissions and there were no recurrences.

Follow-up CT and MRI brain scans demonstrated the disappearance of blood flow signals typical of intracranial venous sinus thrombosis; other abnormal signals and the empty delta sign that. The follow-up scans were all performed between one to three months after presentation and no recurrence of thrombosis was seen in Figures 1-6.

Examination of the coagulation system in all cases showed resolutions of the decreased APTT and PT and increased FDPs after treatment for one to two months with urokinase and LMW heparin. The results of all hematological analyses are given in Table 1.

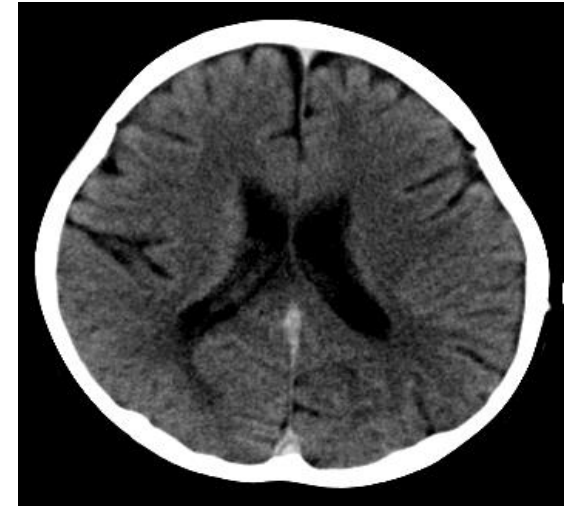

Figure 1: Unenhanced CT scan showing a triangle hyperdensity in the posterior region of the superior sagittal sinus.

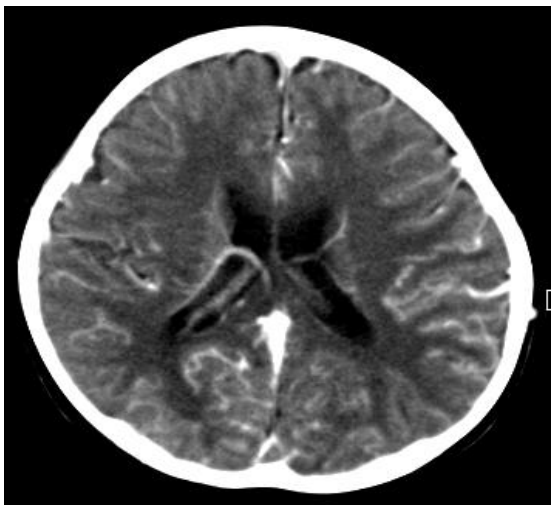

Figure 2: Enhanced CT scan showing a peripheral enhancement in the posrerior region of the superior sagittal sinus with a delta sign filling defect in sinus cavity.

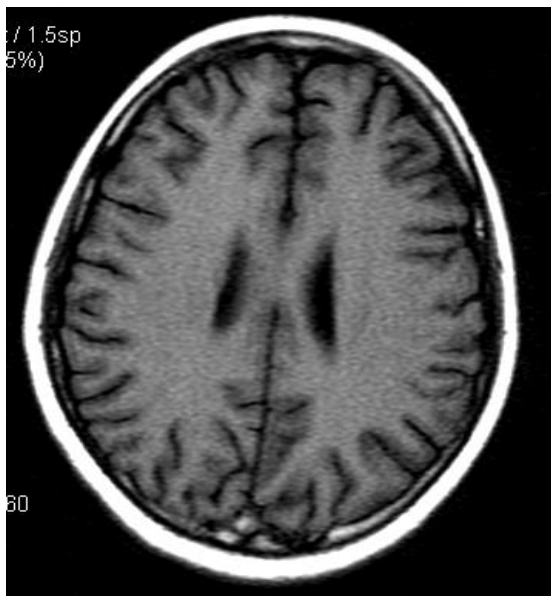

Figure 3: Axial T1-weighted images showing the disappearance of the normal flow void signal in the superior sagittal sinus instead of the short T1 signal.

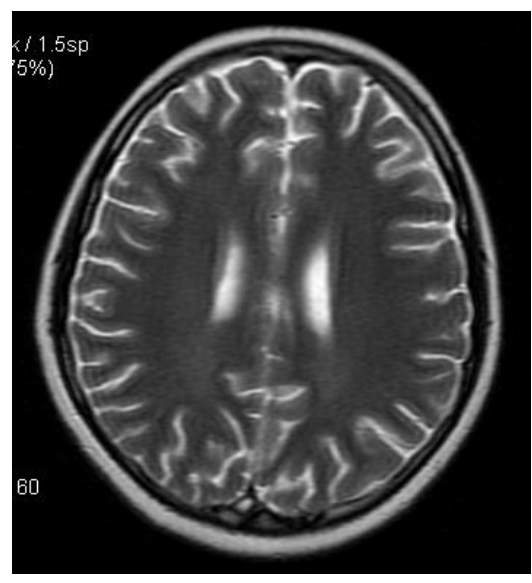

Figure 4: Axial T2-weighted images showing the disappearance of the norma folw void signal in the superior sagittal sinus instead of the long T2 signal.

\section{Discussion}

In NS, the changes that produce the hypercoagulable state and potential thrombosis occur due to a combination of hormonal changes, 
Citation: Xia ZK, Yang X, Fan ZM, Gao YF, Gao C, et al. (2014) Children with Nephrotic Syndrome Suffer from Cerebral Venous Thrombosis. J Nephrol Therapeutic S11: 005. doi:10.4172/2161-0959.S11-005

Page 3 of 4

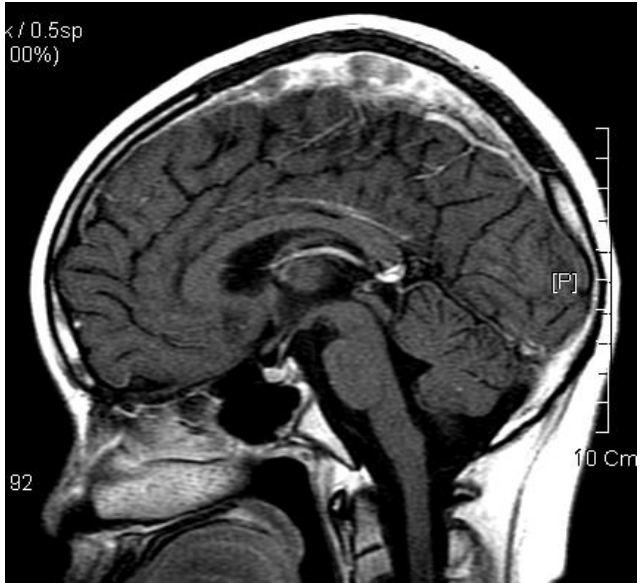

Figure 5: Enhanced T1-weighted images with sagittal scanning showing an oval or funicular filling defect of the superior sagittal sinus.

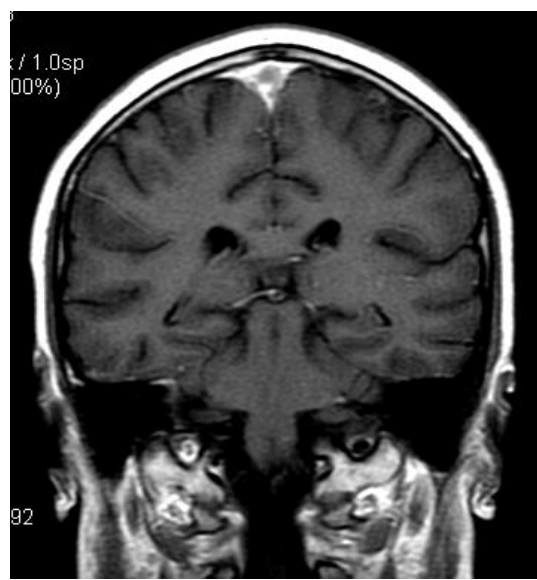

Figure 6: Enhanced T1-weighted images with coronal scanning showing an oval or funicular filling defect of the superior sagittal sinus.

the use of diuretics, and disturbances of the clotting mechanism [9]. The hypercoagulable state is a serious concern in patients with nephrotic syndrome; Renal Venous Thrombosis (RVT) and deep venous thrombosis are serious problems associated with it. Although rare, CVST in children is a particularly serious diagnosis, which can be associated with several underlying systemic conditions; prompt diagnosis is therefore vital. CVST is most commonly identified in the superior sagittal sinus because of its anatomic structure [10]. In previous studies, the incidence of CVST in cases of NS was $1.8 \%-5 \%$, but more recent studies have shown this to be as high as $6.6 \%$. Age is a risk factor and the incidence of CVST is lower in children than it is in adults (20-30\%). Other risk factors for CVST are Steroid-Sensitive Nephrotic Syndrome (SSNS), Steroid-Dependent Nephrotic Syndrome (SDNS), membranous glomerulonephritis and previous thrombosis.

We studied patients diagnosed with NS during treatment with steroids who commonly have hypercoagulability. We recommend paying close attention to the presence of the following clinical signs and laboratory findings: patients with edema and body cavity effusions; plasma albumin $<20 \mathrm{~g} / \mathrm{L}$ or a reversed albumin to globulin ratio; hyperlipidemia, especially when the plasma cholesterol is $>12$ mmol/L; platelet count $>300 \times 9 / 1$; elevated FDPs; decreased APTT and PT; abnormal hemorheology; 10 and the membranous nephropathy or membranoproliferative glomarulonephritis subtypes of NS. DSA is the gold standard for the diagnosis of CVST but its invasiveness and high cost limits its application in clinical practice; cranial CT or MRI combined with MRV is usually performed instead. The basic pathology of phlebothrombosis is the hypercoagulable state in NS. In NS complicated by headache, dizziness, lethargy or vomiting, examination by cranial CT should be performed as soon as possible to diagnose CVST. When administration of the routine dosage of glucocorticoids fails to produce a curative effect in NS, the condition is complicated by hypercoagulability. Anticoagulant therapy should be taken to prevent thrombosis.

The timing of the thrombolysis treatment is critical once thrombosis has occurred. In this serious of patients, we achieved satisfactory effects through combined treatment with urokinase and LMW heparin in cerebral venous thrombosis complicating NS. Urokinase may be separated from healthy human urine or as a single enzyme protein that is extracted from human renal tissue. It can play a direct role in the endogenous fibrinolytic system as it catalyzes the activation of plasminogen which degrades fibrin, fibrinogen and coagulation factors V and VIII in the circulation to exhibit its thrombolytic effect. Thrombolysis by urokinase occurs with a short response time and has good effect [11]. LMW heparin is made from heparin by chemical

\begin{tabular}{|c|c|c|c|c|c|c|c|c|c|c|c|c|c|}
\hline \multicolumn{2}{|l|}{ Item } & \begin{tabular}{|} 
1st case \\
pre- \\
treatment
\end{tabular} & $\begin{array}{c}\text { 1st case post- } \\
\text { treatment }\end{array}$ & $\begin{array}{l}\text { 2nd case } \\
\text { pre- } \\
\text { treatment }\end{array}$ & $\begin{array}{c}\text { 2nd case } \\
\text { post- } \\
\text { treatment }\end{array}$ & \begin{tabular}{|c|} 
3rd case \\
pre- \\
treatment
\end{tabular} & $\begin{array}{c}\text { 3rd case } \\
\text { post- } \\
\text { treatment }\end{array}$ & $\begin{array}{c}\text { 4th case } \\
\text { pre- } \\
\text { treatment }\end{array}$ & $\begin{array}{c}\text { 4th case } \\
\text { post- } \\
\text { treatment }\end{array}$ & $\begin{array}{c}\text { 5th case } \\
\text { pre- } \\
\text { treatment }\end{array}$ & $\begin{array}{c}\text { 5th case } \\
\text { post- } \\
\text { treatment }\end{array}$ & $\begin{array}{c}\text { 6th case } \\
\text { pre- } \\
\text { treatment }\end{array}$ & $\begin{array}{c}\text { 6th case } \\
\text { post- } \\
\text { treatment }\end{array}$ \\
\hline \multicolumn{2}{|c|}{ Proteinuria(g/24h) } & 2.36 & 1.23 & 3.51 & 1.5 & 0.65 & 0.3 & 1.9 & 0.83 & 2.71 & 2.14 & 1.67 & 0.4 \\
\hline \multicolumn{2}{|l|}{$\operatorname{Age}(y)$} & 8 & 8 & 13 & 13 & 10.2 & 10.2 & 9.5 & 9.5 & 13 & 13 & 12.3 & 12.3 \\
\hline \multicolumn{2}{|l|}{ GFR ml/min) } & 84 & 84 & 102 & 102 & 93 & 94 & 86 & 83 & 113 & 110 & 87 & 87 \\
\hline aPTT (s) & $(20-40 S)$ & 12.3 & 18.6 & 14.1 & 20.4 & 12.5 & 22.5 & 10.7 & 17.1 & 16.1 & 27 & 18.3 & 30 \\
\hline $\mathrm{PT}(\mathrm{s})$ & $(12-14 S)$ & 8.5 & 12.5 & 6.3 & 10.4 & 6.2 & 8.6 & 9.1 & 14.2 & 7.3 & 11.3 & 8.6 & 13.1 \\
\hline AtIII $(\%)$ & $(80-120 \%)$ & 60.4 & 61 & 56.2 & 90 & 63.9 & 81.3 & 57.4 & 87.6 & 53 & 71.8 & 63.8 & 81 \\
\hline \multirow{3}{*}{$\begin{array}{l}\text { Whole blood } \\
\text { viscosity } \\
\text { (mPa.S) }\end{array}$} & low shear rate & 12.67 & 9.16 & 14.52 & 10.21 & 12.03 & 9.54 & 13.25 & 10.13 & 12.52 & 9.92 & 11.2 & 10.12 \\
\hline & middle shear rate & 6.07 & 5.12 & 7.45 & 6.49 & 6.71 & 5.46 & 6.84 & 6.01 & 6.79 & 5.73 & 6.58 & 5.92 \\
\hline & high shear rate & 5.05 & 4.38 & 5.79 & 4.81 & 5.28 & 4.27 & 5.61 & 4.79 & 5.36 & 4.35 & 5.29 & 4.72 \\
\hline \multicolumn{2}{|c|}{ Plasma viscosity $(\mathrm{mPa} \cdot \mathrm{S})$} & 1.78 & 1.31 & 1.85 & 1.35 & 1.72 & 1.24 & 1.73 & 1.32 & 1.71 & 1.29 & 1.54 & 1.21 \\
\hline \multirow{3}{*}{$\begin{array}{l}\text { Whole blood } \\
\text { reduced } \\
\text { viscosity } \\
(\mathrm{mPa} \cdot \mathrm{S})\end{array}$} & low shear rate & 21.76 & 19.24 & 24.13 & 20.36 & 21.26 & 19.83 & 22.48 & 20.17 & 21.57 & 19.73 & 20.63 & 19.14 \\
\hline & middle shear rate & 13.29 & 9.16 & 14.2 & 10.25 & 13.43 & 9.48 & 14.21 & 9.62 & 13.72 & 9.73 & 13.38 & 10.25 \\
\hline & high shear rate & 9.25 & 6.46 & 10.71 & 7.32 & 9.46 & 6.41 & 10.06 & 7.18 & 9.82 & 6.72 & 9.28 & 7.34 \\
\hline \multicolumn{2}{|c|}{ RBC aggregation index } & 2.65 & 2.43 & 3.26 & 2.84 & 2.78 & 2.46 & 3.15 & 2.79 & 2.84 & 2.57 & 2.73 & 2.46 \\
\hline
\end{tabular}

Table 1: Changes in the hemorheology before and after treatment with urokinase for patients with intracranial venous sinus thrombosis complicating nephrotic syndrome. 
Citation: Xia ZK, Yang X, Fan ZM, Gao YF, Gao C, et al. (2014) Children with Nephrotic Syndrome Suffer from Cerebral Venous Thrombosis. J Nephrol Therapeutic S11: 005. doi:10.4172/2161-0959.S11-005

Page 4 of 4

treatment or enzymatic depolymerization into derivatives of short polysaccharide chains with molecular weights between 4,000 and 6,500 $\mathrm{Da}$. It possesses a long half-life. LMW heparin plays a significant role in anti-thrombin III and anti-coagulation factor Xa.

In our study, all patients with NS complicated by CVST had the diagnosis confirmed within 48 hours of admission. After the course of treatment with combined LMW heparin and urokinase, the clinical symptoms improved in all patients. One month later, plasma viscosity returned to normal. Shear rates of whole blood viscosity and whole blood reduced viscosity and RBC aggregation index reduced. After one to two months of treatment, the blood coagulation tests returned to normal levels and one to three months later. CT or MRI brain scans confirmed that the cerebral venous sinus thrombosis had disappeared. The results showed that thrombolytic therapy within 48 hours could achieve an ideal effect. The key to successful outcomes in CVSTs that complicate NS is early detection and treatment. Thrombolytic therapy within six hours gives the best results according to studies reported in the literature [12-14].

\section{Conclusion}

In summary, patients with NS should be given routine corticosteroid treatment according to the underlying renal pathology. Anticoagulant therapy should be given as early as possible to patients with hypercoagulability and simultaneous monitoring for phlebothrombosis, especially CVST, should be commenced. Combined treatment of high-dose urokinase impact for fibrinolysis, low-dose maintenance therapy for anti-fibrinolysis, low-molecular-weight heparin and anti-platelet aggregation drugs showed good efficacy and low incidence of hemorrhagic complications. Therefore, the utilization of thrombolytic therapy with combined low-molecular-weight weight heparin and urokinase is worth consideration in general clinic use.

\section{Funding}

This article was supported by Jiangsu Province Key Medical Talent Fund (RC2007115).

\section{References}

1. Loscalzo J (2013) Venous thrombosis in the nephrotic syndrome. N Engl J Med 368: 956-958.

2. Hsu HF, Huang SY (2012) Carotid artery thrombosis in a child with membranous nephropathy associated with factor $V$ Leiden mutation. Pediatr Int 54: 573-574.

3. Barbano B, Gigante A, Amoroso A, Cianci R (2013) Thrombosis in nephrotic syndrome. Semin Thromb Hemost 39: 469-476.

4. Maurin N (2013) [Thromboembolic complications in nephrotic syndrome] Dtsch Med Wochenschr 138: 1123-1129.

5. Babu A, Boddana P, Robson S, Ludeman L (2013) Cerebral infarction in patient with minimal change nephrotic syndrome. Indian J Nephrol 23: 51-53.

6. Bhoobun S, Jalloh AA, Jacobsen KH (2012) Cerebral venous thrombosis in a child with nephrotic syndrome: case report. Pan Afr Med J 13: 57.

7. Wasay M, Bakshi R, Dai A, Roach S (2006) Local thrombolytic treatment of cerebral venous thrombosis in three paediatric patients. J Pak Med Assoc 56: 555-556.

8. Gargah T, Abidi K, Nourchene K, Zarrouk C, Lakhoua MR (2012) [Thromboembolic complications of childhood nephrotic syndrome]. Tunis Med 90: 161-165.

9. Gigante A, Barbano B, Sardo L, Martina P, Gasperini ML, et al. (2012) Hypercoagulability and Nephrotic Syndrome. Curr Vasc Pharmacol.

10. Eddy AA, Symons JM (2003) Nephrotic syndrome in childhood. Lancet 362 629-639.

11. Crassard I, Bousser MG (2004) Cerebral venous thrombosis. J Neuroophthalmol 24: 156-163.

12. Wang IK, Lee CH, Yang BY, Chang HY, Lin CL, et al. (2005) Low-molecularweight heparin successfully treating a nephrotic patient complicated by renal and ovarian vein thrombosis and pulmonary embolism. Int J Clin Pract Suppl : 72-75.

13. Witz M, Lehman J, Shnaker A, Korzets Z (2004) Acute subclavian and brachial artery thrombosis as a complication of the nephrotic syndrome. Isr Med Assoc J 6: 441-442.

14. Sun L, Xu C (2008) Portal vein thrombosis as the first sign of nephrotic syndrome. Nat Clin Pract Nephrol 4: 342-345.
This article was originally published in a special issue, Pediatric Nephrology handled by Editor(s). Moazzam Hossain, Bangabandhu Sheikh Mujib Medica University, Bangladesh 